\title{
Image infrared converters based on ferroelectric- semiconductor thin-layer systems
}

\author{
A. Sosnin \\ Institute of Applied Optics, NAS of Ukraine, 03028 Kyiv, Ukraine
}

\begin{abstract}
Some questions concerning pyroelectric sensors application in microphotoelectronics are considered. Data upon main characteristics of different pyroelectric materials (single crystals, ceramics, thin films) are summarized. Also represented are basic parameters of uncooled pyroelectric thermal vision image converters as a promising direction of the infrared engineering.
\end{abstract}

Keywords: thermal vision, infrarred converter, ferroelectric, pyroelectric, thin-layer system, ceramics.

Paper received 15.01.00; revised manuscript received 07.09.00; accepted for publication 12.12.00.

Electromagnetic radiation of solids heated above absolute zero covers the range from vissible light $(0.75 \mu \mathrm{m})$ to microwave frequences $(\sim 1000 \mu \mathrm{m})$. Most of radiation in this range is absorbed by an ambient atmosphere, therefore, to ensure signal detection, «windows of transparency» in the interval 0.75-15 $\mu \mathrm{m}$ should be used. Detection of longwave IR radiation is of great interest when solving a wide circle of applied problems, namely: from absorption spectra registration in multicomponenet gas mixtures to systems of indication, identification and tracking the heated objects. Herewith, two wavelength regions are of special interest: from 3 to $5 \mu \mathrm{m}$ and 8 to $14 \mu \mathrm{m}$. These are consistent with above «windows of transparency», moreover, the latter is the most interesting one as it corresponds to the radiation maximum of weakly heated bodies with temperature near $300 \mathrm{~K}$ (living beings, machinery, elements of buildings, technological equipment, etc.)

IR detectors convert energy into the form suitable for direct measurements, namely, an electrical signal. As to the mode of such conversion, these are of two types: the heat and photon ones. The majority of recently used serial devices providing sufficient temperature and spatial resolution as well as small time of response was based on photon detectors of IR radiation, for instance, the photovoltaic and photoconducting ones made of cadmium-mercury-telluride and other semiconductor materials. Unfortunately, up to date there exist some unovercome difficulties hindering application of these devices. These are technological complexities in mass production of such materials and devices based on it, and, of major importance, the necessity of operation at low temperatures $(\sim 77 \mathrm{~K})$. As a consequence, it is necessary to use cooling systems, which implies increased overall dimensions, weight, cost and considerable problems under operating conditions.

But in the number of practical applications, when demands to resolution and speed are not extremely high, it is acceptable to use thermal detectors, first of all, the pyroelectric ones. The pyroelectric radiation detectors (PRD) [1-3] are new fastdeveloping class of thermal detectors destined for revealing and measuring electromagnetic radiation in the wide range of wavelengths from $10^{-5}$ to $10^{5} \mu \mathrm{m}$. Although the pyroelectric effect was known for a long time, PRD began to develop much later than radiation thermocouples, bolometers and opticalacoustic detectors. Nowadays their field of applications is considerably extended in comparison with other thermal radiation detectors. PRDs are used in laser and microwave technique, IR radiometry, pyro- and spectrometry, ionizing radiation monitoring and in the fields of the measurement technology. According to the statistical review «USA market of military and commercial IR technology systems», the total output of IR sensors is expected to increase from 658 million dollars in 1994 up to 1400 million dollars in 2001 [4]. An essential part of this growth is associated with the development of pyroelectric instrument making (inspite of expected reduction in their production cost).

PRD development was especially promoted by rapid progress of laser technology metrological provision of which could not be satisfield with measuring means based on radiation detectors known earlier. With laser creation the range of measurable radiation fluxes was extended by more than 15 orders. It became necessary to study pulse radiation with powers up to tens of mega- 
watts, generated within $10^{-6} \ldots 10^{-12} \mathrm{~s}$, current wave radiation with power densities from 1 to $10 \mathrm{~kW} / \mathrm{cm}^{2}$ and spatial radiation distribution. In view of optical heterodyning methods development, it became accessible to solve problems of measuring superweak spectral densities (from $10^{-14}$ down to $10^{-18} \mathrm{~W} / \mathrm{Hz}$ ) of light beams.

PRDs were developed mainly for middle and far IR spectral regions where application of profoelectronic radiation detectors is hindered because of needs to cool them, while other thermal radiation detectors are of slow response. PRDs can successfully compete with them in visible and UV spectral regions as well as in microwave ranges and in measurements of ionizing radiation.

At present PRDs are the most promising type of radiation detectors. It is associated with the fact that along with high sensitivity these possess fast response comparable to that of photodetectors, being simultaneously nonselective thermal detectors. PRDs are universal to some extent as their sensitivity and response can be tuned in wide limits with changing a load resistance. By their nature, PRDs are variable-capacitance transducers, which enables one to make their sensitive elements in the form of fiqures with arbitrary shapes of cone, wedge, sphere and so on, and receiving square demensions from $10^{-4}$ to $10^{6} \mathrm{~mm}^{2}$. Besides, pyroelectric detectors need not special po-wer supply and cryogenic facilities, are rather technolo-gical, stable, reliable and can withstand thermal, mechanical and radiation effects in various operation conditions.

Principle of PRD action is based on the pyroelectric effect consisting in the change of a crystal polarization value with temperature. Among 21 acentric crystal classes, 10 classes are characterized by a special polar axis, are pyroactive and referred to as pyroelectrics. Their main feature is spontaneous polarization in the absence of external fields that is the presence of dipole electric moment different from zero. An essential advantage of PRDs that determines their simplicity and convenience in operation is an anomalously high value of the pyroelectric effect itself in comparison with effects lying in an operational basis of other thermal radiation detectors: the change of sensitive element temperature by $1 \mathrm{~K}$ causes appearance of an electric field up to $10 \mathrm{kV} / \mathrm{cm}$ in it.

The list of main pyroelectric materials used at present time is represented in Table 1. It is seen that the vast majority of exhibited materials are ferroelectics. Their high polarizability provides a large value of spontaneous polarization and high dielectric permeability, and, as a consequence, high induced polarization. Although such a great polarization is not an obligatory condition for a strong pyroelectric effect, it is a very useful property as, in the case, some domains with a strong temperature dependence, particularly near the temperature of a phase transition, can be easily found. High values of dielectric permeabilities are necessary in making multielement PRD arrays and matrices when small dimensions of sensitive elements prevent matching with a preamplifier input impedance.

Choosing any pyroelectric material is mainly determined by requirements placed to the facility as a whole.
Detector performances depend on the whole number of parameters: pyroelectric factor $p$, dielectric permeability $\varepsilon$, loss tangent of dielectric $\operatorname{tg} \delta$, heat capacity per unit volume $c^{\prime}$ that, in their turn, depend on a difference between operating temperature and temperature of their phase transition $T_{c}$. Therefore, to estimate quality of any material and serviceability in solving specific problems, the number of quality criteria was proposed [2]; the following two them are the most important ones: $M_{1}=p / c^{\prime}$, that determines detector sensitivity in a mode of power measurements, and $M_{2}=p / \varepsilon c^{\prime}$ as a factor controlling its sensitivity in a mode of energy measurements.

Tab. 2 shows abovementioned comparative characteristics of conventional pyroelectric materials operating without applying any external electric field at temperatures considerably lower than the Curie point. In most cases these values correspond to typical characteristics of given materials. Up to date, triglycinesulphate doped with alanine and arsenic as well as lead germanate doped with barium have the best characteristics among ferroelectric crystals. Unfortunately, reproducibility of doped crystal characteristicss is not high, moreover, triglycinesulphate is sensitive to moisture exposure. It can explain increased interest to exploration and manufacturing ceramic meterials as more technological and cheap. In chemical composition these can be distinguished as materials of barium titanate, lead zirconate-titanate, niobate and so on. Ceramic materials made of barium niobate and barium titanate possess high piezoelectric factors, but these materials have low temperature stability. Piezoceramic materials based on solid solutions of lead zirconate-titanate (PZT) are the most effective ones at present.

PZT solid solutions are formed in all interval of possible concentrations. Phase diagram of solid PZT comprises several domains: high-temperature (cubic), $P_{\alpha}$; two low-temperature ferroelectric (rhombohedral, $F_{\alpha}$, and tetragonal, $F_{\beta}$ ) as well as ttwo anti-ferroelectric, $A_{\alpha}$ and $A_{\beta}$. A boundary between the tetragonal and rhombohedral ferroelectric phases (the so-called morphotropic boundary) does not practicaly depend on temperature. Compositions situated near to the morphotropic boundary have maximum values of a dielectric permeability, piezoelectric coupling factor, piezomodulus, while values of mechanical quality and frequency factor are minimum. Thermal expantion of PZT polarized ceramics in these compositions is anomalously low at temperatures below the Curie point and equal approximately $(1.5 \pm 0.5) 10^{-6} \mathrm{~K}^{-1}$.

Additives of doping elements, advanced technologies of ceramic making and a polarization process enable to satisty different requirements of designers using this material. PZT ceramics are produced by methods of cold and hot compacting. Hot compacted materials compared to cold-compacted piezoceramics have better piezo- and dielectric properties, density close to a theoretical value, crystals more homogeneous in sizes. For instance, there exist information upon uncooled thermovision cameras operating with hybrid detectors based on modified PZT $\left(\mathrm{PbZr}_{0.58} \mathrm{Fe}_{0.2} \mathrm{Nb}_{0.2} \mathrm{Ti}_{0.02} \mathrm{O}_{3}: \mathrm{U}\right)$ in service today and hav- 


\section{A. Sosnin: Image infrared converters based on ferroelectric- ...}

Table 1. Main pyroelectric materials

\begin{tabular}{lll}
\hline \hline Abbreviation & Name of compound & \multicolumn{1}{c}{$\mathrm{Formula}_{2}$} \\
\hline TGS & Triglycinesulphate & $\left(\mathrm{NH}_{2} \mathrm{CH}_{2} \mathrm{COOH}\right)_{3} \mathrm{H}_{2} \mathrm{SO}_{4}$ \\
\hline DTGS & Deuteried triglycinesulphate & $\left(\mathrm{ND}_{2} \mathrm{CD}_{2} \mathrm{COOD}_{3} \mathrm{O}_{2} \mathrm{SO}_{4}\right.$ \\
\hline ATGSAs & $\begin{array}{l}\text { Triglycinesulphate doped } \\
\text { with arsenic and alanine }\end{array}$ & $\left(\mathrm{NH}_{2} \mathrm{CH}_{2} \mathrm{COOH}\right)_{3} \mathrm{H}_{2} \mathrm{SO}_{4}:$ \\
& Deuteried triglycinefluorineberyllate & $\mathrm{NH}_{2} \mathrm{CH}_{2} \mathrm{CH}_{2} \mathrm{COOH} ; \mathrm{H}_{3} \mathrm{AsO}_{4}$ \\
\hline DTGFB & Kalium tantalate-niobate & $\left(\mathrm{ND}_{2} \mathrm{CD}_{2} \mathrm{COOD}_{3} \mathrm{D}_{2} \mathrm{BeF}_{4}\right.$ \\
\hline KTN & Barium-strontium titanate & $\mathrm{KTa}_{1-\mathrm{x}} \mathrm{Nb}_{\mathrm{x}} \mathrm{O}_{3}$ \\
\hline BST & Barium-strontium-kalium titanate & $\mathrm{Ba}_{1-\mathrm{x}} \mathrm{Sr}_{\mathrm{x}} \mathrm{TiO}_{3}$ \\
\hline BSCT & Strontium-barium niobate & $\mathrm{Ba}_{1-\mathrm{x}-\mathrm{y}} \mathrm{Sr}_{\mathrm{x}} \mathrm{Ca}_{\mathrm{y}} \mathrm{TiO}_{3}$ \\
\hline SBN & Lead titanate & $\mathrm{Sr}_{0.5} \mathrm{Ba}_{0.5} \mathrm{Nb}_{2} \mathrm{O}_{6}$ \\
\hline PT & Calcium-lead titanate & $\mathrm{PbTiO}_{3}$ \\
\hline PCT & Lantanum-lead titanate & $\mathrm{Pb}_{1-\mathrm{x}} \mathrm{Ca}_{\mathrm{x}} \mathrm{TiO}_{3}$ \\
\hline PLT & Lantanum-lead zirconate-titanate & $\mathrm{Pb}_{1-\mathrm{x}} \mathrm{La}_{\mathrm{x}} \mathrm{TiO}_{3}$ \\
\hline PLZT & Lead zirconate-titanate & $\mathrm{Pb}_{1-\mathrm{x}} \mathrm{La}_{\mathrm{x}}\left(\mathrm{Zr}_{1-\mathrm{y}} \mathrm{Ti}_{\mathrm{y}}\right)_{3} \mathrm{O}_{3}$ \\
\hline PZT & Zirconate-titanate modified with lead & $\mathrm{Pb}_{1-\mathrm{x}} \mathrm{Zr}_{1-\mathrm{x}} \mathrm{Ti}_{\mathrm{x}} \mathrm{O}_{3}$ \\
\hline PZFNTU & Modified lead zirconate-titanate doped & $\mathrm{PbZr}_{0.58} \mathrm{Fe}_{0.2} \mathrm{Nb}_{0.2} \mathrm{Ti}_{0 / 02} \mathrm{O}_{3}: \mathrm{U}$ \\
\hline PSZFTNTU & with strontium & $\mathrm{Pb}_{1-\mathrm{x}} \mathrm{Sr}_{\mathrm{x}} \mathrm{Zr}_{0.58} \mathrm{Fe}_{0.2} \mathrm{Nb}_{0.2} \mathrm{Ti}_{0.02} \mathrm{O}_{3}: \mathrm{U}$ \\
\hline PScT & Lead scandium-tantalate & \\
\hline PMN & Magnesium-lead niobate & $\mathrm{PbSc}_{0.5} \mathrm{Ta}_{0.5} \mathrm{O}_{3}$ \\
\hline PZN & Lead zinc-niobate & $\mathrm{PbMg}_{1 / 3} \mathrm{Nb}_{2 / 3} \mathrm{O}_{3}$ \\
\hline PNZT & Solid silution of lead zirconate-titanate & $\mathrm{PbZn}_{1 / 3} \mathrm{Nb}_{2 / 3} \mathrm{O}_{3}$ \\
\hline PcoW & and lead zinc-niobate & $\mathrm{PbZr}_{1-\mathrm{x}-\mathrm{y}} \mathrm{Zn}_{\mathrm{x} / 3} \mathrm{Nb}_{2 \times / 3} \mathrm{Ti}_{\mathrm{y}} \mathrm{O}_{3}$ \\
\hline PGO & Lead cobalt-tungstate & \\
\hline \hline
\end{tabular}

ing not so bad characteristics: their equivalent noise temperature is $0.25 \mathrm{~K}$ in a matrix with $100 \times 100$ elements [5].

Thereshold sensitivity of all thermal radiation detectors can be improved by decreasing thickness of a sensitive element. However, though diminishing a film thickness can decrease its specific heat, reaching maximum possible characteristics of pyroelectric detectors is restrained by the fact that, starting from definite thicknessec, one has aggravation of ferroelectric film parameters as compared to properties of respective bulk materials. It can be explained by violation of grating periodicity near a ferroelectric boundary and associated with it arising mechanical strains and electric fields as well as by carrier diffusion from an electrode material into the contact region. Therefore, as the greatest success in the field of ferroelectric materials science, one could take elaboration of manufacturing technology for thin micron and submicron films. This technology is compatible with standard semiconductor microelectronic technologies including operations in surface treatment, thinning, polishing, sectioning, metallization and thermal insulation of systems consisting of $10^{4}$ elements (aligned with respective elements of multichannel integrated circuit) and combining such incosistent properties as a low noise level and superhigh input impedance (up to $10^{12} \mathrm{Ohm}$ ). Nowadays, thin films of lead titanate, both pure and lanthanum doped ones, possess properties approaching to those of the best ceramics based on solid solutions of lead zirconate-titanate.

Taking into account that electrical characteristics of ferroelectrics, including spontaneous polarization, effectively depend on external electric fields, one can control parameters of pyroelectric detectors. As a rule, this way is also used in the case when a phase transition temperature $T_{c}$ lies within the range of detector operation temperatures. In this case, polarization induced by an electric field both above and below $T_{c}$ can exceed the spontaneous one. Therefore, devices of this type are often referred to as dielectric bolometers in literature. An analogous operation mode can be also realized without application of any external electric field when the direction of material polarization in a sensitive element prepared, 
Table 2. Normal pyroelectrics $\left(T<T_{c}\right)$

\begin{tabular}{|c|c|c|c|c|c|c|c|c|}
\hline Material & $\begin{array}{l}T_{c} \\
{ }^{\circ} \mathrm{C}\end{array}$ & $\begin{array}{c}c^{\prime} \\
\mathrm{J} / \mathrm{cm}^{3} \mathrm{~K}\end{array}$ & $\begin{array}{c}p \\
\mu \operatorname{Coul} / \mathrm{cm}^{3} \mathrm{~K}\end{array}$ & $\stackrel{a}{a}$ & $\operatorname{tg} \delta$ & $\begin{array}{c}M_{1} \\
\mathrm{~cm}^{2} / \mathrm{Coul}\end{array}$ & $\begin{array}{c}M_{2} \\
\mathrm{Vcm}^{2} / \mathrm{J}\end{array}$ & References \\
\hline \multicolumn{9}{|c|}{ Single crystals } \\
\hline TGS & 49 & 2.3 & 0.028 & 38 & 0.01 & 3620 & 0.066 & {$[6]$} \\
\hline DTGS & 60 & 2.4 & 0.055 & 43 & 0.02 & 6020 & 0.083 & [7] \\
\hline ATGSAs & 51 & 2.5 & 0.07 & 32 & 0.008 & 9900 & 0.19 & [8] \\
\hline $\mathrm{LiTaO}_{3}$ & 665 & 3.2 & 0.18 & 43 & 0.003 & 1440 & 0.051 & [9] \\
\hline $\mathrm{LiNbO}_{3}$ & 1210 & 3.0 & 0.083 & 28 & 0.005 & 1140 & 0.025 & [9] \\
\hline SBN 46/54 & 132 & 2.1 & 0.043 & 380 & 0.003 & 610 & 0.065 & [9] \\
\hline PGO:Ba & 70 & 2.0 & 0.032 & 81 & 0.001 & 2200 & 0.19 & [10] \\
\hline
\end{tabular}

Ceramics

\begin{tabular}{lcccccccc} 
PLZT 7/65/35 & 150 & 2.6 & 0.13 & 1900 & 0.015 & 300 & 0.032 & {$[11]$} \\
\hline PLZT 8/65/35 & 105 & 2.6 & 0.18 & 4000 & 0.003 & 190 & 0.066 & {$[12]$} \\
\hline PZNFTU & 230 & 2.7 & 0.039 & 290 & 0.0031 & 570 & 0.052 & {$[13]$} \\
\hline PSZNFTU & 170 & 2.7 & 0.049 & 400 & 0.0028 & 520 & 0.058 & {$[13]$} \\
\hline PGO & 178 & 2.6 & 0.002 & 25 & 0.003 & 350 & 0.009 & {$[14]$} \\
\hline
\end{tabular}

Polymers

\begin{tabular}{lllllllll} 
PVDF & - & 2.4 & 0.0027 & 12 & 0.015 & 1040 & 0.009 & {$[10]$} \\
\hline
\end{tabular}

\section{Thin films}

\begin{tabular}{lcccccccc}
$\mathrm{PbTiO}_{3}$ & 490 & 2.9 & 0.095 & 200 & 0.02 & 1870 & 0.056 & {$[15]$} \\
\hline PLT 90/10 & 330 & 3.2 & 0.065 & 200 & 0.006 & 1150 & 0.062 & {$[16]$} \\
\hline PCT 70/30 & 270 & 3.3 & 0.05 & 390 & 0.015 & 440 & 0.021 & {$[17]$} \\
\hline PZT 54/46 & 380 & 3.1 & 0.07 & 950 & 0.016 & 260 & 0.019 & {$[15]$} \\
\hline \hline
\end{tabular}

for instance, in the form of an epitaxial film, is determined by its preliminary orientation.

Among mass applications of pyroelectric defectors one should separate protective signalling facilities, power saving devices, i.e. «automatic switches», and pyroelec-tric thermo-vision cameras. The former two types of devices are based on operation of an executive element under action of a pyroelectric signal arising due to temperature field changes in controlled apartments. These are widely used all over the world for last two decades, and their output have reached several million units per year.

The third direction is comparatively new. Despite that the first pilot samples of uncooled portable thermo-vision cameras came into being near the boundary between $80 \mathrm{~s}$ and $90 \mathrm{~s}$, these have already attracted interest of reliable producers. The most important fields of applications for such facilities are the following: night vision, reconnaissance, objective recognition, car driving, protective systems, process monitoring and so on.
During 70-80s most attention was concentrated on developing and applying pyroelectric vidicons, that is cathode-ray tubes based on pyroelectric materials [28-34]. From the early 90s the new direction using matrix hybrid pyroelectric-semiconductor structures is effectively developed $[35,36]$. One of the first acting device based on modified lead zirconate-titanate made in the form of an PRD matrix placed on multichannel silicon integrated circuit was described by Shorrocks and Edwards [5] in 1990. As a result, quite competitive portable pyroelectric infrared cameras were developed. These are capable to provide television quality of an image. Costs of the cameras are an order of magnitude less than that of traditional cooled systems. In this sence, the Texas Instruments experience in development of pyroelectric converters $[18,37]$ is rather instructive. Pioneer works at uncooled heat converters were begun there in the middle 70s. Considerable results were achieved in 1987 when a demonstrative sample was capable to provide tempera- 


\section{A. Sosnin: Image infrared converters based on ferroelectric- ...}

Table 3. Pyroelectric materials for PRD operating in the vicinity of a phase transition temperature point

\begin{tabular}{|c|c|c|c|c|c|c|c|c|c|c|}
\hline Material & $\begin{array}{l}\text { Bias } \\
\mathrm{kV} / \mathrm{cm}\end{array}$ & $\begin{array}{l}T_{c} \\
{ }^{\circ} \mathrm{C}\end{array}$ & $\begin{array}{c}c^{\prime} \\
\mathrm{J} / \mathrm{cm}^{3} \mathrm{~K}\end{array}$ & $\begin{array}{c}p \\
\mu \mathrm{Coul} / \mathrm{cm}^{3}\end{array}$ & ${ }^{3} \mathrm{~K}$ & $\operatorname{tg} \delta$ & $\begin{array}{c}M_{1} \\
\mathrm{~cm}^{2} / \mathrm{Cou}\end{array}$ & $\begin{array}{c}M_{2} \\
\mathrm{Vcm}^{2} / \mathrm{J}\end{array}$ & & References \\
\hline \multicolumn{11}{|l|}{ Single crystals } \\
\hline DTGFB & 0 & 74 & 2.0 & 1.4 & 2400 & 0.02 & \multicolumn{2}{|r|}{3300} & 0.34 & [18] \\
\hline KTN 67/33 & 2.5 & 4 & 3.7 & 8.0 & 25000 & 0.002 & 1000 & 0.46 & & [19] \\
\hline BST $67 / 33$ & 5 & 5 & 2.5 & 0.3 & 20000 & 0.007 & 170 & 0.034 & & [10] \\
\hline \multicolumn{11}{|l|}{ Ceramics } \\
\hline BST $67 / 33$ & 1 & 21 & 3.2 & 23.0 & 31000 & 0.028 & 2700 & 0.84 & & [18] \\
\hline BST $67 / 33$ & 2 & 22 & 3.2 & 6.3 & 33000 & 0.021 & 670 & 0.25 & & [18] \\
\hline BST $67 / 33$ & 6 & 24 & 3.2 & 0.70 & 8800 & 0.004 & 280 & 0.12 & & [18] \\
\hline BST $65 / 35$ & 40 & 29 & 2.5 & 0.10 & 1200 & 0.0013 & 380 & 0.11 & & {$[10]$} \\
\hline PMN:La & 90 & 40 & 3.0 & 0.085 & 1200 & 0.0008 & 800 & 0.10 & & {$[10]$} \\
\hline PScT & 53 & 40 & 2.7 & 0.38 & 2900 & 0.0027 & 550 & 0.17 & & [19] \\
\hline PZT 94/6* & 0 & 50 & 2.6 & 0.37 & 300 & 0.02 & 5300 & 0.19 & & [20] \\
\hline PZT 90/8/2* & 0 & 30 & 2.6 & 0.185 & 290 & 0.019 & 2800 & 0.10 & & [21] \\
\hline $\begin{array}{l}\text { PCT 70/30:PCoW } \\
96 / 4\end{array}$ & 0 & 106 & 3.3 & 3.07 & 400 & 0.037 & 1380 & 0.18 & & {$[22]$} \\
\hline $\begin{array}{l}\mathrm{PZN} / \mathrm{BT} / \mathrm{PT} \\
80 / 10 / 10^{* *}\end{array}$ & 0 & 12 & 2.7 & 5.93 & 4670 & 0.01 & 5310 & 1.08 & & {$[23]$} \\
\hline $\begin{array}{l}\text { PZN/BT/PT } \\
80 / 10 / 10\end{array}$ & 0 & 85 & 2.7 & 2.9 & 18300 & 0.018 & 660 & 0.20 & & [23] \\
\hline
\end{tabular}

\begin{tabular}{lccccccccc}
\hline $\begin{array}{l}\text { Thin films } \\
\text { PScT (deposition) }\end{array}$ & 40 & 40 & 2.7 & 0.52 & 6000 & 0.012 & 360 & 0.076 & {$[24]$} \\
\hline PScT (sol-gel) & - & 40 & 2.7 & 0.30 & 7000 & 0.002 & 180 & 0.10 & {$[25]$} \\
\hline PScT & 20 & 40 & 2.7 & 0.08 & 1000 & 0.002 & 330 & 0.07 & {$[26]$} \\
\hline KTN & 30 & 40 & 3.7 & 20.0 & 1200 & 0.01 & 50000 & 5.0 & {$[27]^{* * *}$} \\
\hline \hline
\end{tabular}

* transition between two rhombohedric phases

** transition between rhombohedric and tetragonal phases

*** data are doubtful

ture resolution close to $0.5 \mathrm{~K}$. For next stages this work was included into the number of state programs and got some considerable financial support. As a result, a set of devices for military and civil purposes was produced. In Fig. 1 shown schematically are a fragment of the pyroelectric structure consisting of $80.000(245 \times 328)$ elements and lying in the basis of portable infrared thermal-vision camera «Night Sight» mounted on a patrole police car [37]. A matrix of sensitive elements 1 is made of a bariumstrontium titanate plate using laser scribing.

Interelement space and distance between element centers are equal to 10 and $48.5 \mu \mathrm{m}$, respectively. After scribing, the plates are etched for skimming slags, then these are annealed in oxygen atmosphere to recover stoichiometry. Depositiion of the absorbing cover 4 consisting of the parylene film 6, semitransparent 5 and opaque common to all elements 7 electrodes as well as recovering flatness of the scribed surface acomplish treatment of the side receiving infrared emission. The film-electrodes SQO, 3(4), 2000

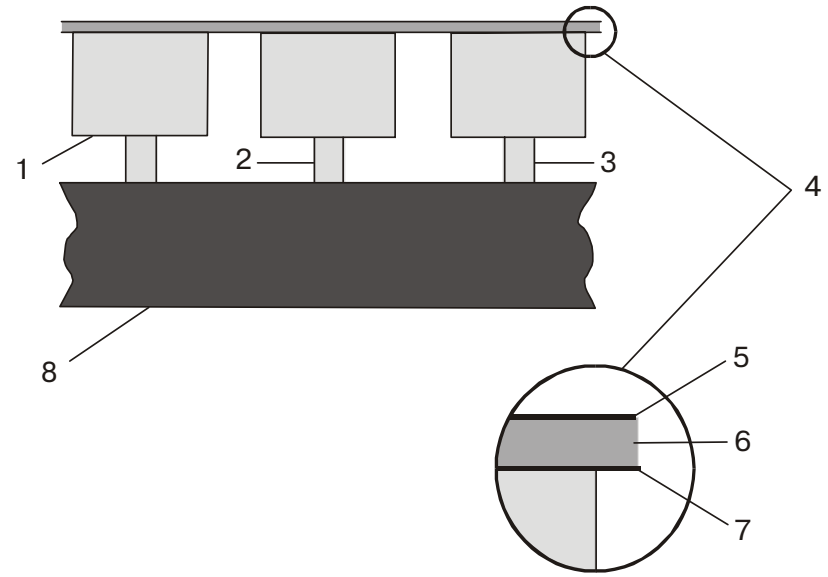

Fig. 1. Schematic view of a pyroelectric matrix fragment: $1-$ sensitive element; 2 - basis; 3 - conductive coating; 4 - absorbing coating; 5 - parylen; 6 - semitransparent electrode; 7 opaque electrode; 8 - integrated circuit. 


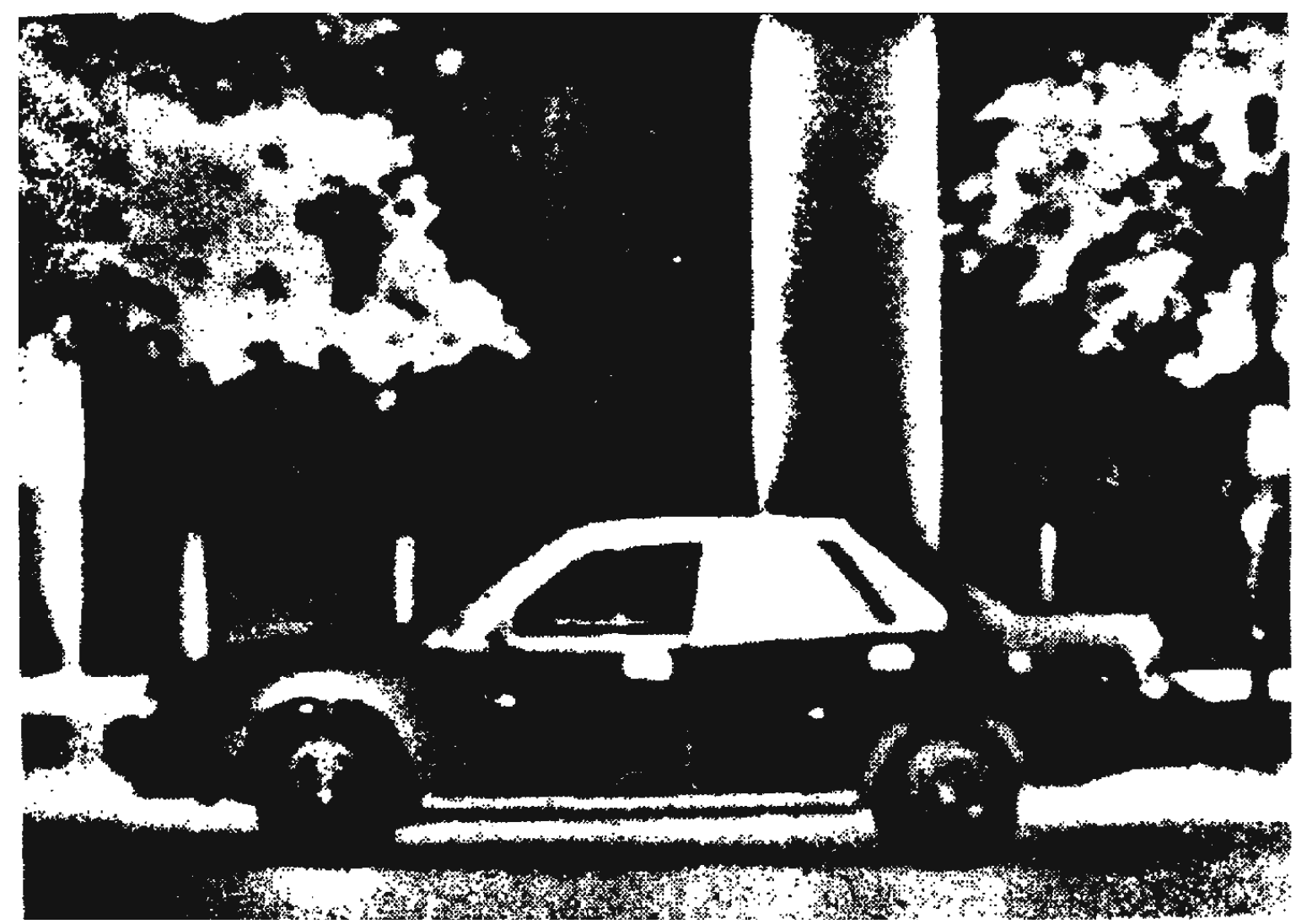

Fig. 2. Infrared image of a car obtained by using a detector with equvallent temperature $0.2^{\circ} \mathrm{C}$ and optics of $f / 1.0$ type [18].

system forms some resonance cavity that provides absorption coefficient not worse than $90 \%$ in the range of 7.5 to $13 \mu \mathrm{m}$. To reduce heat losses form the rear side, each sensitive element is placed on the tiny base 2 , surface of which is covered by conducting layer 3 providing an electrical contact with an input of respective channel of the matching integrated circuit 8 . Preamplifiers are inverting stages with feedback resistances of the order of $10^{11}-10^{12} \mathrm{Ohm}$. Outputs of each amplifier are gated in such manner that the matrix output is compatible with standard television facilities. The matrix is mounted on mono-stage thermoelectric cooler and placed into standard case with dimensions $25 \times 24 \times 6 \mathrm{~mm}^{3}$ having 40 leads. This device provides an image uniformity not worse than $1.5 \%$. Obtained data are acceptable for representing them both on indoor displays and on the outdoor ones. An example of infrared image is shown in Fig. 2. Main technical performances of the camera are summarized in Tab. 4.

The cost of this device in batch production is equal approximately to $\$ 6,000$. Since 2000 the company Rayteon plans to equip Cadillac cars with similar thermovision cameras developed in Texas Instruments [14]. In experts' opinion, it will be one of essential stages in the development of automatic control systems in car transportation that should be one of the main spheres of IRsensors application by 2010-2015 years.
Table 4. Performances of the thermal-vision camera "Nightsight"

\begin{tabular}{ll}
\hline \hline Field of view angle & $28 \times 18$ \\
\hline Depth of field & $\begin{array}{l}\text { From } 6 \mathrm{~m} \text { to infinity } \\
\text { (at fixed focus) }\end{array}$ \\
\hline Type of videointerface & RS170/NTSC \\
\hline Automatical functions & Contrast and brightness \\
\hline Image polarity & Arbitrary \\
\hline Readiness time & $<30 \mathrm{~s}$ \\
\hline Temperature range & From $-20^{\circ} \mathrm{C}$ to $+50^{\circ} \mathrm{C}$ \\
\hline Maximum temperature & $105^{\circ} \mathrm{C}$ \\
of ambient air & $6 \mathrm{~W}$ \\
\hline Power consumption & $12 \mathrm{~V}=/ 24 \mathrm{~V} \sim($ on choice) \\
\hline Supply voltage & $\mathrm{Waterproof}$ \\
\hline Case type & $20.4 \mathrm{~cm} \times 15.2 \mathrm{~cm} \times 15.2 \mathrm{~cm}$ \\
\hline Dimensions & $<2.25 \mathrm{kgf}$ \\
\hline Weight & $<0.12^{\circ} \mathrm{C}$ \\
\hline Equivalent noise & \\
temperature & $5^{\prime}$ \\
\hline Angle resolution & \\
\hline \hline
\end{tabular}




\section{A. Sosnin: Image infrared converters based on ferroelectric- ...}

Thus, uncooled sensors that up to date were of a most limited application become a basis for a new branch of photoelectronics, namely, uncooled thermal vision. The following progress in the field of pyroelectric detectors should be associated with searching new effective materials, elaborating methods of making thin ferroelectric films and improving technologies of manufacturing hybrid structures based on ferroelectric-semiconductor systems.

\section{References}

1. V.F. Kosorotov, L.S. Kremenchoogskiy, V.B. Samoilov, L.V. Shchedrina, Pyroelectric effect and its application, (in Russian), Naukova dumka, Kiev, 1989, 324p.

2. L.S. Kremenchoogskiy, O.V. Roitsina, Pyroelectric defectors of radiation, (in Russian), Naukova dumka, Kiev, 1979, 381p

3. L.S. Kremenchoogskiy, O.V. Roitsina, Pyroelectric receiving devices, (in Russian), Naukova dumka, Kiev, 1982, 363p.

4. S.F. Weiss, IR sensors growth predicted // Photonics spectra // June 1995. pp.58-60.

5. N.M. Shorrocks and I.M. Edwards, Design and performance of thermal imaging arrays // Proc. 7th Int. Symp. Appl. Ferroelectrics, IEEE // pp. 58-62, (1990).

6. J.M. Herbert, Ferroelectric transucers and sensors // Gordon and breach science publishers Inc. // pp. 266-240, (1983).

7. R.W. Whatmore, Pyroelectric ceramics and devices // in Electron, Ceram. edited by B, C. H. Steele, Elsevier, London, pp. 169-184, (1991).

8. R.W. Whatmore. Pyroelectric ceramics and devices for thermal infrared detection and imaging // Ferroelectrics // vol. 118, pp. 241-259, (1991).

9. A.S. Bhalla, C.S. Fang and L.E. Cross, Pyroelectric properties of alanine and Deuterium substituted TGSP and TGSAs single crystals // Maier. Lett. // vol. 3, pp. 475-477, (1985).

10. R. L. Byer and C. B. Roundy, 'Pyroelectric coefficient direct Measurement technique and application to a NSEC response time detector // Ferroelectrics // vol. 3, pp. 333-338, (1972).

11. R.W. Whatmore, P.C. Osbond and N.M. Shorrocks, Ferroelectric materials for thermal IR detectors // Ferroelectrics // vol. 76, pp. 351-367, (1987).

12. S.T. Liu, J.D. Heaps and O.N. Tufte, The pyroelectric properties of the Lanthanum-doped ferroelectric PLZT ceramics // Ferroelectrics // vol. 3, pp. 281-285, (1972).

13. K.K. Deb, Investigation of pyroelectric characteristics of mollified $\mathrm{PbTiO}$, ceramics for improved IR detector performance // Ferroelectrics // vol. 88. pp. 167-176, (1988).

14. P.C. Osbond and R.W. Whatmore, Improvements to pyroelectric ceramics via strontium doping of the lead zirconatelead iron Niobate-lead titanate system // Ferroelectrics // vol. 118, pp. 93-101, (1991).

15. A. Kanduser, M. Kosec, A. Levstic and B.B. Lavrencic, $\mathrm{Pb}_{5} \mathrm{Ge}_{3} \mathrm{O}_{11}$ ceramics pyroeleclric detector // Proc. 7th Int. Symp. Appl, Ferroelectrics // IEEE, pp. 383-386, (1990).

16. C. Ye, T. Tamagawa and D.L. Polla, Experimental studies on primary and secondary pyroelectric effects, in $\mathrm{Pb}_{1-\mathrm{x}} \mathrm{Zr}_{\mathrm{x}} \mathrm{TiO}_{3}$, PbTiO, and $\mathrm{ZnO}$ thin films // J. Appl. Phys. // vol. 70, pp. 55385543, (1991).

17. D. L. Polla, C. Ye and T. Tamagawa, Surfaced-micromachined $\mathrm{PbTiO}_{3}$, pyroelectric detectors // Appl. Phys. Lett. // vol. 59, pp. 3539-3541, (1991).

18. R. Takayama, Y. Tomita, K. Lijima and I. Ueda, Pyroelectric properties and application to infrared sensors of $\mathrm{PbLaTiO}_{3}$, $\mathrm{PbZrO}_{3}$ and ferroelectric thin films // Ferroelectrics // vol. 118. pp. 325-342, (1991).

19. E. Yamaka, H. Watanabe, H. Kimura, H. Kanaya and H. Ohkuma, Structural, ferroelectric and pyroelectric properties of highly c-oriented $\mathrm{Pb}_{1-\mathrm{x}} \mathrm{Ca}_{\mathrm{x}} \mathrm{TiO}_{3}$, thin film grown by radio-frequency magnetron sputtering // J. Vac. Sci. Tedmol // vol. A6. pp. 2921-2928, (1988).

20. B.M. Kulvicki, A. Amin. H.R. Beratan and C.M. Hanson, Pyroeleclric imaging // Proc. $8^{\text {th }}$ IEEE Int. Symp. Appl. Ferroelectrics // pp. 1-10, (1990).

21. M. Shorrocks, R.W. Whatmore and P.C. Osbond, Lead scandium tantalate for thermal detector applications // Ferroelectrics // vol. 106, pp. 387-392, (1990).

22. M. Shorrocks and R.W. Whalinore, Ferroelectric materials / / Brit. UK Pat. Appl. GB 2, 240, 335, July 31, (1991).

23. J. Lian. K. Okumura, M. Adachi. T. Shiosaki and A. Kawabata, Mixed sintering of $\mathrm{PbZrO}_{3}$, rich PZT based ceramic and their pyroelectric properties // Proc. 7th Int. Symp. Appl. Ferroelectrics, IEEE // pp. 383-386, (1990).

24. R. Watton, Ferroelectric materials and devices in infrared detection and imaging // Ferroelectrics // vol. 91, pp. 87-108, (1989).

25. R. Watton and M.A. Todd, Ferroelectric ceramics for infrared detection // Brit. Ceram. Proc. // vol. 41, pp. 205-217, (1989).

26. K.K. Deb, Pyroelectric materials, U.S. patent 4.983.839, January 8, (1991).

27. K.K. Deb, Investigation pyroelectric characteristic of $8 \mathrm{~Pb}\left(\mathrm{Zn}_{1 / 3} \mathrm{Nb}_{2 / 3}\right) \mathrm{O}_{3}-0.1 \mathrm{PbTiO}_{3}-0.1 \mathrm{BaTiO}_{3}$, ceramics with special references to uncooled infrared detection // J. Electron. Mat. // vol. 2C pp. 653-658, (1991).

28. R. Watton and M.A. Todd, Induced pyroelectricity in sputtered lead scandium tantalate films and their Merit for IR detector arrays // Ferroelectrics // vol. 118, pp. 279-295, (1991).

29. N.M. Shorrocks, S.U. Porter, K.W. Whatmore, A.D. Parsons, J. N Gooding and D.J. Pedder, Uncoolcd infrared thermal detector arrays // Proc. SPIE - Int. Soc. Opt. Eng. // vol. 1320 Infrared technology and applications, pp. 88-94, (1990).

30. F.W. Ainger, C.J. Brierley. M.D. Hudson, C. Trundle and R. W Whalmore, Ferroelectrics thin films by metal organic chemical vapour deposition // Mat: Res. Soc. Symp. Proc. // vol. 200, pp. 37-47, (1990).

31. N.W. Schubring, J.V. Mantese, A.L. Micheli, A.B. Catalan and R.J. Lopez, Charge pumping; and Pseudopyroelectric: effect in activ ferroelectrics Relaxor-Type films // Phys. Rev. Lett // vol. 68. pp. 1778-1781, (1992).

32. M.E. Lines and A.M. Glass, Principles and applications, of ferroelectrics and related materials, Clarendon Press, Oxford, 1977, pp. 561-578.

33. H. Pulley, Thermal detectors, in topics in applied physics, vol. 19: Optical and infrared detectors, R. J. Keycs, editor, Sprintier-Verlag. New York, pp. 71-100, 1980

34. J. M. Herbert, Ferroelectrics transducers and sensors // Gordon and breach science publishers inc. // pp. 266-290, 1982.

35. R. Watton, C. Smith and G.R. Jones, Pyroelectric materials: Operation and performance in the pyroelectric camera tube // Ferroelectrics // vol. 14, pp. 719-721, 1976.

36. R. Watton, Ferroelectrics for infrared detection arid imagine // Proc. 6th Int. Symp, Appl. -Ferroelectrics, IEEE // pp. 172-181, 1986.

37. W. Whatmore, Pyroelectric devices and materials // Rep. Prog. Phys. // vol. 44, pp. 1335-1386, 1986.

38. Watton, Ferroelectrics materials and devices in infrared detection and imagine // Ferroelectrics // vol. 91, pp. 87-108, 1989

39. L.A. Berardinis, Night vision, Mach. Des., October 24, 1991, pp. 57-61: J. M. Callahan. Sight at night, Automotive Ind., October 1991, pp. 30 ff: J. Haystead, Thermal Imaging, Defense Elecir., April, pp.48-52, (1991)

40. S. Borrello, Focal planes for infrared imaging, Texas Inst. Tech. J., vol. 8, pp.20-27, (1991).

41. C. Hanson and H.Beratan, Uncooked pyroelectric imaging, Proc. 9th IEEE. Int. Symp. Appl. Ferroelectrics // pp. 656661, (1990).

42. R.W. Hardin, First automobile with IR imaging hits the road in 2000 // OE Reports // № 184, April 1999, pp. 1-4. 